\title{
ANNUAL SURVEY OF QUÉBEC'S PUBLIC LIBRARIES: A MAJOR REVISION
}

Benoit Allaire, Observatoire de la culture et des communications du Québec

Geneviève Baril, Ministère de la Culture, des Communications et de la Condition féminine

Marie-Josée Benoit, Bibliothèque et Archives nationales du Québec

\begin{abstract}
In 2008, a major revision to the annual survey of public libraries (Enquête annuelle sur les bibliothèques publiques - EBP) was carried out jointly by the Ministère de la Culture, des Communications et de la Condition féminine (MCCCF) and Bibliothèque et Archives nationales du Québec (BAnQ), with the support of the Observatoire de la culture et des communications du Québec (OCCQ).

Data from the annual survey were revised and standardized in compliance with the international standard ISO 2789 on library statistics, and to meet the needs and expectations of Québec's library community. The standardized and updated survey better reflects the services offered by Québec's public libraries, especially as it concerns electronic services, and it provides performance indicators at national and international levels. It also allows those involved to make the best possible use of the data by greatly increasing the outlets for this information and the means of disseminating it.

In addition, the process for collecting and disseminating statistics is now done using a statistical information system supported by a data warehouse, an Internet interface and a report generator. Now that this system has been set up, library managers, administrators of public library policies and programs and interested researchers have rapid access to statistical information that can be easily used for carrying out comparative analysis and management activities.
\end{abstract}

\section{BACKGROUND}

The gathering of data from Québec's public libraries by the Ministère de la Culture, des Communications et de la Condition féminine (MCCCF) dates back to 1961. Historically, data collection was part of the management of the MCCCF's financial support programs for autonomous public libraries ${ }^{1}$ and regional service centres for public libraries, ${ }^{2}$ and it made it possible for statistics on Québec's public libraries to be published annually.

Call for collections development projects from autonomous public libraries.

2 Operational support for regional service centres for public libraries. 
To give some idea of the Québec public libraries the statistics were about, here is a summary profile of the network in 2006:

- 125 autonomous public libraries, ${ }^{3}$ using 316 service points, served slightly more than 6 million inhabitants, which represented $83.1 \%$ of the population served;

- 690 libraries $^{4}$ affiliated with 11 regional service centres for public libraries (CRSBP, also called Réseaux BIBLIO), with 741 service points, served slightly more than 1.2 million inhabitants, which represented $16.9 \%$ of the population served;

- Bibliothèque et Archives nationales du Québec had and has, as one of its mandates, to provide leading edge services to all Quebecers and to all public libraries in Québec.

Until 2006, the MCCCF was solely responsible for all stages in the production of statistics on Québec public libraries. In 2007, it felt the time was right to call on the expertise of two partners in order to increase the quality of the statistics, standardize them and broaden their dissemination. To accomplish this, the MCCCF brought itself into association with Bibliothèque et Archives nationales du Québec (BAnQ), given that the latter, a government corporation, has a mandate to strengthen cooperation between libraries and has professional expertise and a technological infrastructure that enable it to be very active in new initiatives and new services for Québec libraries. The two partners also sought the consulting services of the Observatoire de la culture et des communications du Québec (OCCQ), which, since 2000, under the auspices of the Institut de la statistique du Québec, has overseen the production and dissemination of official statistics on culture and communications in Québec.

It does not go without saying that a statistics agency will take part in the production and dissemination of statistics on public libraries. In many countries - notably France - statistical data are compiled by the government agency responsible for libraries, while, in others - Switzerland, for example - it is the national statistics agency's role to collect and disseminate public library data. Until recently, the first model prevailed in Québec, and it is also the one found in the other provinces of Canada.

The specific roles and responsibilities of each of the three partners, all of whom participated in planning a new automated statistical information system and in revising the questionnaire for Québec public libraries, can be summarized as follows:

The MCCCF coordinated the partnership. It participated in the various stages of the new process.

Autonomous public libraries (BPA) generally serve municipalities with populations greater than 5,000 .

4 The libraries affiliated with the Réseaux BIBLIO generally serve municipalities with populations less than 5,000. 
BAnQ was responsible for the questionnaire itself and for updating it. It gathered the information using a Web application that provides for data collection, consultation and extraction.

The OCCQ played an advisory role regarding the methodological aspects of the survey (particularly data validation and estimation) and the interpretation of the statistical results.

In short, the objective of the three-party collaboration consisted in bringing together the services and competencies of the three public institutions concerned the MCCCF, BAnQ and the OCCQ - in order to optimize the process of producing, disseminating, keeping and analysing statistics on Québec's public libraries. The three teams also had a common concern for producing standardized statistics in line with international standards and the needs and expectations of the Québec documentary community. In addition, the partnership offered each of the three participating institutions the possibility of using and disseminating the data according to its own methods, which provided for more widespread and better use of the statistics gathered.

\section{THE REVISED, STANDARDIZED ANNUAL SURVEY}

In 2008, the desire for change became a reality. Québec's public libraries responded to a questionnaire that was automated and revised in accordance with ISO 2789, the international standard on library statistics. The 2007 annual survey was composed of standardized questions and it more adequately took account of the services offered by libraries, notably electronic ones. The questionnaire - the first component of the statistical information system - was well received by library staffs when it was placed online. Staffs also had the benefit of a support service attentive to their needs. The service proved very useful, particularly in a context of change.

The structure of the questionnaire is based essentially on the divisions of the ISO standard:

- Collection - stock and additions

- Library use and users

- Access and facilities

- Library staff

- Information technologies

- Expenditure

In Québec as elsewhere, public libraries are expanding their traditional service offering by adding electronic services, which users are discovering and using more all the time. Statistics collection must keep pace with this change in order to measure the totality and diversity of the services available. That is why the questionnaire now includes questions making it possible to list electronic collections, 
measure the use of electronic services and provide financial data on acquisition expenditures for electronic collections, particularly databases, periodicals and electronic books. The illustration (Figure 1), taken from the 'Library use and users' section, shows some of the new additions.

The survey results relating to these emerging services include a high rate of null values, for the time being, mainly due to difficulties in providing the data. Though anticipated, these results highlight the challenge to libraries with regard to the collection of data on the use of electronic resources.

\section{METHODOLOGY AND DATA VALIDATION}

With regard to the methodological aspects, the OCCQ took part in developing the questionnaire, designed the data validation rules and calculated estimated values to compensate for partial non-response. The data validation, apart from the coherence validation and the professional validation (under BAnQ responsibility), also consisted in assessing the probability of observing certain discrepancies with respect to the data of previous years for the comparable questions on the 2007 survey and previous years' surveys. When a piece of data appeared too improbable, the library concerned was contacted again to confirm or modify it.

Although the response rate to the survey can attain $100 \%$, which will happen when all libraries complete the form, some questions remain unanswered - for all sorts of reasons. This is what is called partial non-response. Statistical procedures make it possible to calculate values to compensate for partial non-response and thereby produce statistics more in line with reality. To illustrate, a library may be unable to say how many children's titles it has in its collection, which does not mean it has no works of that type. The results are sure to be more realistic if it is assumed the library has a certain number of children's titles, than if it is taken for granted it has none, even if the estimate will very likely be somewhat off the mark. Statistical methods allow the probability of the estimate to be determined.

Though not always indicated in public library statistics, the use of estimates to compensate for partial non-response is a normal procedure in a large number of statistical surveys. It is necessary in order to avoid systematic bias toward underestimation of the variables measured and brings the non-negligible advantage of making it possible to establish valid diachronic comparisons, since non-response is not constant over time.

\section{DISSEMINATION AND USE OF STATISTICAL DATA}

It was agreed that consultation and dissemination of the statistics, in addition to data collection, would be handled using a statistical information system relying on a data storage application, a Web interface and a report generator. The system is 
intended to accelerate access to statistical data that can be used readily for analysis and management purposes. Users are offered various possibilities for consulting the annual survey data. All source data, except for nominative data, and a series of performance indicators are accessible for purposes of consultation and the production of customized reports. A selection of reliable and significant performance indicators (currently about 20 of them) complement the data table and present the information in a way that facilitates interpretation of the results.

Starting from a structured menu, users can chose one or more libraries with the help of various other menus (by municipality, region or population category) and select a certain number of data items. The results can be displayed as a table or graph, and then be printed and exported in CSV format.

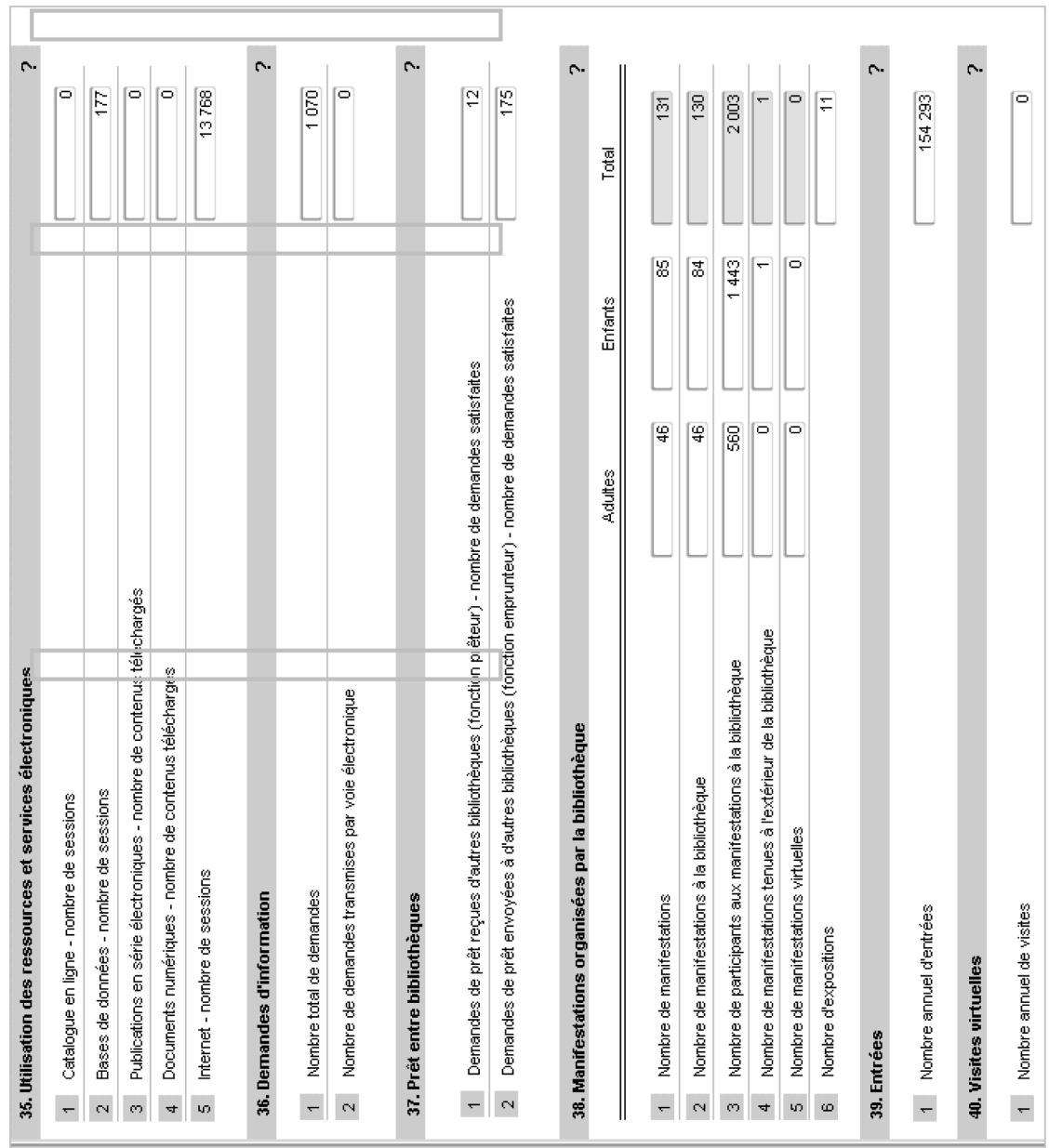

Figure 1: 'Library use and users' section of the annual survey 
In addition, there are options for viewing records containing a selection or the totality of statistical data for a given library. To illustrate, the summary record gives a representative profile of a library, combining key data on the collections available and services offered, and on the use of the collections and services. It provides quantitative data, together with a certain number of performance indicators (loans per inhabitant, visits per inhabitant, Web sessions per inhabitant, etc.). The graphics-enhanced schematic and visual form of these records makes them suitable for a variety of informational and promotional uses in relations with decision-making authorities.

The numerous improvements made to the annual survey help provide quality statistics that are exhaustive and quickly accessible to all - library managers, funding agencies and library users. Thanks to an innovative partnership, the new annual survey on Québec's public libraries is a successful operation providing for a more dynamic statistical data collection process, mainly through the use of tools that track the evolution of libraries, their dynamism and their will to offer quality services to the populations they serve. 